\section{J. Mantas}

Laboratory of Health Informatics, University of Athens, Athens, Greece

\title{
Research and Education
}

\section{Health Informatics Education and Research at the University of Athens}

\begin{abstract}
In Europe, coordinated activities in healthcare informatics education started in the late 1980s with the establishment of European courses in health telematics. At the same time the European Commission foresaw the need for spreading the knowledge of Information Technology (IT) in the healthcare sector. Therefore the EC, since then, has supported the initiatives that aim to create awareness, stimulate diffusion, and educat and train the users (healthcare professionals) in the application of IT in health care [1]. Initiatives, such as the NIGHTINGALE project, are essential for the planning and implementation of strategies for training the nursing profession in using and applyin. healthcare information systems. Other projects are the IT EDUCTRA project, which is a practical project in the field of education and training of healthcare professionals in information technologies, and the ERASMUS Master's Course, which aims at giving those working (or intending to work) in the health service and related activities, a broad advanced postgraduate education in health informatics.
\end{abstract}

Keywords:Education, Health Informatics, Nursing

\section{Introduction}

Without doubt, the terms education and training (E\&T) and health care are top issues in every forum related to information and communication technologies (ICTs). Health informatics is an emerging and important multidisciplinary field that involves not only Informatics but also medicine, nursing, engineering, biology and other related subjects.

The University of Athens (National and Kapodistrian University of Athens) was the first University established in Greece in modern times (1837). It has become the largest university in Greece with about 1,700 professors and lecturers, 800 administrative personnel and 70,000 undergraduate and postgraduate students.

The Laboratory of Health Informatics, which is attached to the De- partment of Community Medicine of the Faculty of Nursing, was established in 1987. The Laboratory is wellequipped with $25 \mathrm{PCs}$ connected to PC/NFS Network having a Sun Sparcstation as server with TCP/IP and Internet communication facilities. The Laboratory also has an Internet node with a connection of $512 \mathrm{Kbps}$.

The Laboratory of Health Informatics serves the undergraduate and postgraduate studies of most of the Schools of Health Sciences of the University of Athens. Also, it runs the international course in health informatics under the auspices of the ERASMUS program. More than 12 $\mathrm{PhD}$ candidates and $25 \mathrm{MSc}$ postgraduate students use the facilities of the Laboratory to finalize their project dissertations or thesis research work.

The Laboratory of Health Informatics is greatly involved in major
European Commission funded project such as:

- ERASMUS Inter-University Cooperation Programs,

- COMETT (Health-Info and Mim Projects),

- DGXIII-AIM (Eurodiabeta Euclides, Games, Precise, Teles nursing),

- DGXIII-Telematics for Health Care (Nightingale, IT Eductra Telenurse),

- DGXIII-Telematics for Education and Training (COAST),

- DGV-Social Funds (Health Infor matics Training Programmes to health professionals at hospitals) The Laboratory is also involved in national projects of the Ministry of Research and Technology and the Ministry of Health.

In the following we will focus on three initiatives. 


\section{The ERASMUS Master} Course in Health Informatics

The course is held at the National d Kapodistrian University of Aththis, Medical School campus, at the Goudi suburb of the city of Athens. The campus is situated close to the major hospitals of Athens. The proram runs under the auspices of the Faculty of Nursing of the University of Athens.

The following European Universithes actively participate in the course by sending professors as well as enroling students for the course' :

The aim of the course is to give those working (or intending to work) in the health service and related activities a broad, advanced postgraduate education in health informatics in order to develop the ability to understand and evaluate in detail the theoretical and practical requirements of informatics in medicine, nursing, and health care and to solve information-related problems arising from the dramatic advancement of technology as it is being applied in health care across Europe.

The course is relevant to those holding a degree in one of the clinical sciences, life sciences, or physical sciences, such as: Medicine, Nursing, Dentistry, Pharmacology, Physiology, Pathology, Biochemistry, Biology, Biophysics, Pharmacy, Sociology of Health, Engineering, Computer Science, Mathematics, Microbiology, Clinical Chemistry, and Health Economics, as long as they are all university graduates.

The graduate will acquire:

- a good theoretical background in relevant aspects of basic scientific and health disciplines which interact with the application of information science and technology to the acquisition, processing, interpretation, storage, and communication of health data, in both health education and research, and in patient care;

- a thorough training in scientific method so that a problem may be assessed, experimental studies designed, available systems evaluated and a scientific or technical report prepared;

- an ability to understand the scientific basis of clinical and engineering problems encountered in medical, nursing and health care and a better understanding of the use of computers and knowledge-based computing methods;

- an ability to investigate advanced problems and to undertake research in health informatics [2].

\subsection{Entry Requirements}

Entrance to the course can be gained by those university graduates holding degrees in medicine, nursing and other health-care related professions, as well as in Engineering and Computer science who wish to work in the health service area. Graduates of any medical, nursing or health-related discipline, engineering, computer science or natural science may apply. Relevant experience in the health sciences will be taken into account for people with a non-health related educational background. Applicants should demonstrate excellent command and knowledge, of both oral and written English language.

\subsection{Course Pattern}

The course is available for full-time students and will subsequently lead to the award of the MSc. in Health Informatics. Full-time students will attend for one full calendar year. Lectures and laboratory exercises will be held from Mondays to Fridays at the Medical School Campus of the University of Athens.
The course comprises a total of 600 formal contact hours; lectures take 350 hours and there are 250 hours of laboratory exercises. Lectures and laboratory exercises start in October and end in May. Successful students need a further academic year (depending on home country regulations) to complete the research project and submit a dissertation.

\subsection{Lecture Course}

The program comprises 600 hours of formal lectures given by distinguished professors and lecturers of the participating universities. All lectures are given in a lecture room specially dedicated to the ERASMUS course. The course is organized in 13 modules, all of which are compulsory. The lecture material is distributed to all students before the start of each module. A total of 3,000 pages of course and didactic material is distributed to the students. The content of the course is organized to give the students competence in making decisions in solving healthcare problems related to informatics. To fulfil this, the students must acquire knowledge, skills and attitudes. Therefore, an important principle of the course is to develop the ability for life-long independent learning and understand the principles of health informatics as they are applied to the informatics field. Such competence means that the student shall be able to:

1. Identify his or her learning needs.

2. Evaluate critically different sources of information.

3. Evaluate his or her learning in relation to the needs.

The educational methods used in the MSc course have been selected to train the students in the skills listed above. The learning is directed by objectives. The students have the main

\footnotetext{
Contributions from: University of Gent, Free University of Brussels, University of Leuven, Johannes-Keppler University of Linz, University of

Madrid, University of Torino, Technical University of Milano, Trinity College of the University of Dublin, University of Patras, N.T.U. of Athens,

Ghiversity of Piraeus, UMDS and LSE of the University of London, City University, University of Manchester, University of Glasigow, University

Copenhagen, University of Limburg, University of Oulu, University of Tampere and University of Athens.
} 
responsibility to attain the competence level set and have freedom to choose between the various learning resources offered in the Laboratory of Health Informatics. Teaching staff stimulates and guides active learning in various ways. The studies are to a large extent problem-based. Computer-based cases are used to focus on problems arising in the different modules. The structure of the modules is the following:

1. Introduction to health informatics and standards.

2. Health sciences and health care delivery.

3. Biostatistics, health research methods.

4. Medical decision making.

5. Biomedical simulation.

6. Healthcare systems.

7. Health economics.

8. Hospital information systems and telemedicine.

9. Mathematical modelling in medicine.

10. Biomedical equipment.

11. Signal processing and medical imaging.

12. Development of information and DBMS systems.

13. Knowledge-based systems in health care.

\subsection{Laboratory Exercises}

All students can work under DOS/ Windows and/or Unix environments. Related health informatics applications and computer-assisted learning software is available to the students. International computer networks (INTERNET/ EARN/ BITNET/ JANET) can be reached through Email facilities. Terminals connected to the mainframe computer (Convex) are situated on the campus. CD-ROM based library access is also available. The newest strategy used in the MSc course includes the use of Internet, which supports a variety of services, protocols and applications offered by other networks, each of which has a different purpose. Major ones include
E-mail, ftp, and the World Wide Web. All these facilities, which are provided freely to the students, are available at the medical school campus. Furthermore, the Department of Informatics, situated at the main university campus, can provide further facilities, such as imaging, and expert systems laboratories.

\subsection{Research Project}

All students will undertake a research project as part of the MSc course. The aim of the project is to provide the student with an opportunity to undertake research work applying appropriate concepts, methods and techniques of health informatics to a particular problem. The research work will be carried out at the home university. Exceptionally, the project may be undertaken with one of the other partners (e.g. where cooperative research is being carried out between that partner and the home university partners). In that case the student selects a research topic from those available within the home university and under the supervision of one or more professors finalizes and submits the dissertation at the home university.

\subsection{Examinations}

The 13 modules are examined by means of five 3-hour written papers. Two examination papers are taken after Christmas and the remainder after the Easter Holidays. All examination papers are considered of equal importance. The certificate of completion of the MSc course will be awarded to students who:

- obtain a minimum of $45 \%$ in each of the five 3-hour written papers

- obtain a minimum aggregate of $50 \%$ in the papers

- obtain a minimum of $50 \%$ for the dissertation.

\subsection{Course Evaluation}

During the six-year existence of the course, 120 students were enrolled.
Students came from different Euro pean countries, including Greece, th United Kingdom, the Netherland Spain, Belgium, Ireland, Finland, Swa den, Rumania, and the Republic a China. The students showed an active interest in supporting the various learn ing experiences and were actively is volved in several social and culture events in Greece provided by the coos dinating university.

\subsubsection{Evaluation by students}

The lecturers of each of the 13 modules are encouraged to seek feed back from the students as an evaluf tion of the modules, both in terms content and delivery, has been achieve by a questionnaire and direct feedbad from the students to the staff. Studer evaluation takes place both during the course and after its completion eacl year. The evaluation is a major way of receiving feedback by the studen improving, thereafter, the contents and delivery of the course.

\subsubsection{Evaluation by staff}

Staff fromclinical and technical disciplines share the tutorship. Membet of staff provide course evaluation by written comments and discussions with members of the Steering Committed The Steering Committee consists of one representative from each of the participating universities. The coord nating University of Athens chairs the Steering Committee.

\subsection{Other Experiences}

There are other European cours] in the field of health and medic informatics. In the U.K. a medid informatics course is running at the University in London. This course ist Master's Course for full-time or pt time students coming from all ovg Europe after having fulfilled the entul requirements. The ERASMUS MSI course, coordinated by the Universil of Athens, is in close cooperation will the above-mentioned course with ext 
hange of students and staff. Another ourse running in the U.K. is at the Giversity of Glasgow. The same kind of liaison also exists with this university and the University of Athens.. Wellknown MSc and PhD courses in mediGal informatics are running at the Rrasmus University Rotterdam, the Wetherlands.

\subsection{Future Development}

From 1998, the ERASMUS MSc course will continue to run under the new EU initiative, namely the SOCRATES/ERASMUS program. This program is more centralized than its predecessor and we envisage some administrative problems; however, efforts are being made not to influence the smooth running of the academic part of the course.

In addition, the Ministry of Education of Greece has recently agreed financing of a proposal submitted to improve and enhance the existing course in cooperation with eight additional Greek university faculties ${ }^{2}$.

\section{The NIGHTINGALE Project}

TheNIGHTINGALE projectis based on previous experiences and user needs as described in the deliverables of the Telenursing project of the previous phase of AIM, as well as of the EDUCTRA concerted action [3] which partially addressed the education and training of the nursing profession.

The project has as its main goal to identify, by means of a series of workshops, the user needs of the nursing profession in telematics, which for many years have been neglected even though being the largest user group of health care professionals. The board on the faser needs of the consortium and the expert panels will provide curricula of nursing informatics focused on various target groups of the nursing profession, and will implement the curricula at a number of demonstration (training) centers across Europe. The implementation phase will use courseware that will be developed based on existing teaching material using multimedia development tools.

\subsection{Scope and Objectives}

The scope of this project is to provide curriculum development in the multi-disciplinary field of nursing informatics by a consensus process at all levels of nursing education and training, as well as implementation and demonstration of the curriculum throughout Europe [4]. The objectives of the NIGHTINGALE project are:

- To survey the existing situation of nursing informatics in Europe and register the existing courses.

- To investigate the status of nursing curricula related to informatics courses across Europe.

- To identify the knowledge in informatics of the nursing profession in Europe.

- To organize a series of user workshops to study and identify user needs and comment.

- To organize workshops of nursing information systems providers in order to identify the needs of training in nursing informatics.

- To organize workshops of nursing informatics education and training computer-based systems providers.

- To develop curricula of nursing informatics for nurses employed by healthcare organizations, and for students studying nursing in nursing schools, colleges or universitybased education of nursing.

- To verify and demonstrate curriculum development approach of nursing informatics at various institu- tional sites and hospitals.

- Tointegrate multimediaeducational and training approaches in nursing informatics.

\subsection{Phases of the Project}

The project follows the five-stage life-cycle model of the Telematics Application Program of the European Union [5]:

\section{Analysis of user requirements}

The analysis of user requirements is mainly based on previous work of other European projects. In addition, consensus workshops of users will be organized and the outcomes will be merged with previous experiences.

II. Definition of functional specifications

The outcome of the previous user requirements will be formally described in specifications of the training and educational processes needed, and in specifications of the training material required in nursing informatics.

\section{III.Building of a demonstrator}

There are two parallel processes: (a) the finalization of the nursing informatics curriculum targeted to various user groups, and (b) the development of courseware material in nursing informatics using multimedia tools. $I V$. Validation of the demonstrator

The two previously described processes will merge in the validation phase which will have two sub-phases: (a) the verification phase where the training material along with the curriculum will be implemented and then verified, leading to minor adjustments, and (b) the demonstration phase where the final material and curriculum will be implemented in a large number of nursing informatics training or educational sites.

\section{$V$. Exploitation plan}

The courseware and curriculum will become available to all the universities and colleges of nursing education across

The universities participating in this initiative are: the University of Athens (Departments of Nursing, Informatics, and Economics), University of Thessaloniki (School of Engineering), University of Ioannina (Department of Medicine), University of Piraeus (Departments of Informatics, and, rechnology) and the Economics University of Athens (Department of Informatics). 
Europe; communication of the final results and outcomes will be provided to the Council of Europe to issue recommendations for nursing informatics education in Europe; network availability of the courseware and updates of the material will be available through Internet, and market research for the provision of courseware to publishing companies will be undertaken.

\subsection{Outcomes}

The NIGHTINGALEobjectives will be achieved as follows [4]:

- Creation of an operational World Wide Web server in nursing informatics(http://www.dn.uoa.gr/ nightingale).

- Evaluation of the existing authoring material on nursing informatics.

- Development of curriculum in nursing informatics and courseware material as transparency packages.

- Development of CD-ROM CBT software for nursing information systems, terminology in nursing informatics and nursing practice.

- Development of courseware packages with introductory aspects of nursing informatics with related booklets.

- Publishing a textbook on nursing informatics, as well as yearly proceedings of the NIGHTINGALE conferences and workshops.

- Training nurses through the implementation of the courses $(3,000$ nursing professionals are expected).

\section{The IT EDUCTRA project}

IT EDUCTRA integrates members and knowledge of several previous projects and consortia in health care, education and training on information technologies (in DELTA, AIM, ERASMUS, COMMET, etc.). Specifically, the project takes as its main starting point the results and recommendations of the previous EDUCTRA AIM-phase Concerted Action and its analysis of the needs of education and training in ITs in the health care sector. EDUCTRA concluded that most healthcare professionals have inadequate knowledge of the principles of health informatics. Health professionals use their PCs for word processing, managing databases and producing graphics, but assessment of their knowledge on the functions of health information systems in particular, and of the possibilities and limitations of information systems in general, shows their knowledge to be inadequate.

The main objective of ITEDUCTRA is to establish a European-wide training program for healthcare professionals addressing the basics of IT and IT medical applications, with a final goal of getting an audience of some thousands of beneficiaries [5].

In addition, quantitative objectives of the project include:

- around 75 information and training products that are newly created, some of them in full multimedia format, distributed as CD-ROMs and using Web technology

- first audiences will be at least in English, German, French, Italian and Spanish, but also in Portuguese, Finnish, Danish, Dutch and other European languages

- 14 diffusion sites for the demonstration phase

- 10 courses per diffusion site

- 8 seminars per diffusion site.

\section{Conclusions}

The Telematics Applications Program is a key part of the EU's strategy of support for building Europe's information society. With its focus on meeting the needs of users, the program has helped improving the delivery of services of public interest, promote the competitiveness of European industry, and stimulate job creation.

In the healthcare sector, telematics applications can improve clinical ef- fectiveness, and continuity and quality of care by the full range of healthcare and health service management pros fessions.

The University of Athens has ace knowledged the importance of the edw cation in the new disciplines of health and nursing informatics, playing a critio cal role in implementing and adopting the new telematics applications in healthcare.

\section{References}

1. De Moor GJE. Standardisation in health care informatics and telematics in Europe CEN TC 251 activities. In: De Moor GJE, McDonald CJ, Noothoven van Goor J, eds. Progress in Stand. in Health Care Inform. Amsteram: IOS Press, 1993: 1-13.

2. Diomidus M, Mantas J. ERASMUS mas. ter of science in health informatics. In: Mantas J., ed. Health Telematics Educe tion. Amsterdam: IOS Press 1997: 33-3려

3. Hasman A. State of the art report on education and telematics in the health care sector. In: Mantas J, ed.Health Telematid Education. The Netherlands: IOS Press 1997: 3-6.

4. Mantas J. The NIGHTINGALE project An outline. In: Mantas J, ed. Healti Telematics Education. Amsterdam: IOS Press, 1997: 7-25.

5. Gaitan Pacheco R. IT EDUCTRA-int酒 mation technologies education and train ing. In: Mantas J, ed. Health Telematid Edu. Amsterdam: IOS Press, 1997: 26-32

Address of the author:

Prof. John Mantas,

Lab. of Health Informatics,

University of Athens,

P.O.Box 77313 ,

GR-17510 Athens, Greece 